\title{
Life history predicts flight muscle phenotype and function in birds
}

\author{
Shane G. DuBay ${ }^{1,2}$ (i) | Yongjie Wu ${ }^{3}$ | Graham R. Scott ${ }^{4}$ | Yanhua Qu ${ }^{5}$ | Qiao Liu ${ }^{6}$ | \\ Joel H. Smith ${ }^{7}$ | Chao Xin ${ }^{8}$ | Andrew Hart Reeve ${ }^{9}$ | Chen Juncheng ${ }^{3}$ | Dylan Meyer ${ }^{7}$ | \\ Jing Wang ${ }^{5,10}$ | Jacob Johnson ${ }^{7}$ | Zachary A. Cheviron ${ }^{11}$ | Fumin Lei, ${ }^{5,10}$ | John Bates ${ }^{2}$
}

${ }^{1}$ Committee on Evolutionary Biology, University of Chicago, Chicago, IL, USA; ${ }^{2}$ Integrative Research Center, Field Museum of Natural History, Chicago, IL, USA; ${ }^{3}$ Key Laboratory of Bio-resources and Eco-environment of Ministry of Education, College of Life Sciences, Sichuan University, Chengdu, China; ${ }^{4}$ Department of Biology, McMaster University, Hamilton, ON, Canada; ${ }^{5}$ Key Laboratory of Zoological Systematics and Evolution, Institute of Zoology, Chinese Academy of Sciences, Beijing, China; ${ }^{6}$ Institute of Mountain Hazards and Environment, Chinese Academy of Sciences, Chengdu, China; ${ }^{7}$ Department of Ecology and Evolution, University of Chicago, Chicago, IL, USA; ${ }^{8}$ Laboratory of Molecular Evolution and Molecular Phylogeny, College of Life Sciences, Shannxi Normal University, Xi'an, China; ${ }^{9}$ Biosystematics Section, Natural History Museum of Denmark, University of Copenhagen, Copenhagen, Denmark; ${ }^{10}$ University of Chinese Academy of Sciences, Beijing, China and ${ }^{11}$ Division of Biological Sciences, University of Montana, Missoula, MT, USA

Correspondence

Shane G. DuBay

Email: dubaysg@umich.edu

Yongjie Wu

Email:wuyongjie@scu.edu.cn

\section{Present address}

Shane G. DuBay, Department of Ecology and Evolutionary Biology, University of

Michigan, Ann Arbor, MI, USA

\section{Funding information}

Sichuan University; Society for the Study of Evolution; Animal Behavior Society; American Museum of Natural History; National Natural Science Foundation of China, Grant/Award Number: 31501851 and 31630069; American Ornithological Society; American Philosophical Society; Paulson Institute; National Geographic Society/Waitt Fund; Field Museum; Chinese Academy of Sciences, Grant/Award Number: XDB13020300

Handling Editor: Daniel Ardia

\section{Abstract}

1. Functional traits are the essential phenotypes that underlie an organism's life history and ecology. Although biologists have long recognized that intraspecific variation is consequential to an animals' ecology, studies of functional variation are often restricted to species-level comparisons, ignoring critical variation within species. In birds, interspecific comparisons have been foundational in connecting flight muscle phenotypes to species-level ecology, but intraspecific variation has remained largely unexplored.

2. We asked how age- and sex-dependent demands on flight muscle function are reconciled in birds. The flight muscle is an essential multifunctional organ, mediating a large range of functions associated with powered flight and thermoregulation. These functions must be balanced over an individual's lifetime.

3. We leveraged within- and between-species comparisons in a clade of small passerines (Tarsiger bush-robins) from the eastern edge of the Qinghai-Tibet Plateau. We integrated measurements of flight muscle physiology, morphology, behaviour, phenology and environmental data, analysing trait data within a context of three widespread, adaptive life-history strategies-sexual dichromatism, age and sexstructured migration, and delayed plumage maturation. This approach provides a framework of the selective forces that shape functional variation within and between species.

4. We found more variation in flight muscle traits within species than has been previously described between species of birds under $20 \mathrm{~g}$. This variation was associated with the discovery of mixed muscle fibre types (i.e. both fast glycolytic and fast oxidative fibres), which differ markedly in their physiological and functional attributes. This result is surprising given that the flight muscles of small birds are 
generally thought to contain only fast oxidative fibres, suggesting a novel ecological context for glycolytic muscle fibres in small birds. Within each species, flight muscle phenotypes varied by age and sex, reflecting the functional demands at different life-history stages and the pressures that individuals face as a result of their multi-class identity (i.e. species, age and sex).

5. Our findings reveal new links between avian physiology, ecology, behaviour and life history, while demonstrating the importance of demographic-dependent selection in shaping functional phenotypic variation.

\section{KEYWORDS}

animal behaviour, functional traits, intraspecific variation, phenology, phenotypic variation, physiology, seasonal migration

\section{1 | INTRODUCTION}

Functional traits are the essential phenotypes (physiology, morphology, phenology, etc.) that impact survival, growth and reproduction (Violle et al., 2007), and underlie the life history and ecology of an individual. Although single traits can be critical to an organism's fitness (Grant \& Grant, 2002; Jones et al., 2018; Storz, 2018), they do not evolve in isolation-they are parts of complex systems that must balance multiple functional demands. These demands, however, can vary markedly by species, age and sex, which together impact the ways in which traits evolve and co-vary in populations (Bolnick et al., 2011). While we have a general understanding of how age and sex impact explicitly reproductive traits in animals, we know little about how these demographic axes shape other essential traits that are more broadly associated with an organism's behaviour and ecology. In this study, we leveraged withinand between-species comparisons in a clade of small passerines to test how age- and sex-dependent demands on function are reconciled in the avian flight muscle, an essential multifunctional organ in birds.

\section{1 | Functional demands on the avian flight muscle}

The avian flight muscle has a pervasive impact on life history and ecology in birds, modulating diverse sets of other functional traits that span morphology, physiology, behaviour and phenology (Dakin, Segre, Straw, \& Altshuler, 2018; Rayner, 1988; Scott, Egginton, Richards, \& Milsom, 2009). The flight muscle facilitates a large range of functions associated with powered flight and thermoregulation, as birds generate endogenous heat through muscle shivering (Marsh \& Dawson, 1989). As the dominant muscle associated with flight, the pectoralis major is responsible for generating lift and thrust, and it accounts for the majority of muscle mass in birds (Biewener, Dial, \& Goslow, 1992). The pectoralis is thus inextricably linked to life history and essential ecological tasks, like seasonal movements, foraging/prey capture, predator avoidance, social interactions and thermoregulation. The pectoralis must consequently balance the diverse functional demands on powered flight and thermoregulation (Dakin et al., 2018; Rosser \& George, 1986; Scott et al., 2009; Segre et al., 2015).

Comparative methods have uncovered striking variation in flight muscle form and function that reflect taxon-specific selection on flight performance (Dakin et al., 2018; Rosser \& George, 1986). For example, bar-headed goose (Anser indicus) populations that migrate over the Himalayas have accumulated changes in their pectoralis phenotype that seem to enhance aerobic capacity and tissue oxygen supply to support prolonged flight under extreme hypoxia (Hawkes et al., 2011; Scott et al., 2009). In hummingbirds, variation in flight muscle size contributes to functional differences in flight performance and manoeuvrability (Dakin et al., 2018; Segre et al., 2015). In comparison, island birds, which often face reduced predation pressure, have evolved smaller pectoralis muscles than continental relatives. These differences could reflect a cost or a need for regular use to maintain flight muscles, and they underscore the functional role of flight muscles in predator avoidance (Wright, Steadman, \& Witt, 2016). Studies comparing species with contrasting ecologies, such as these, have been foundational in connecting flight muscle phenotypes to species-level ecology, but critical variation that exists within species remains largely unexplored. Without considering selection on flight muscle function along intraspecific axes, like age and sex, we are limited in our ability to address fundamental questions about the processes that shape phenotypes over the evolutionary history of a lineage and over the lifetime of an individual.

By accounting for variation along intraspecific axes of age and sex, we can test how multiple shifting demands on flight muscle function are reconciled across the lifetime of an individual and between sexes. When used in concert with interspecific comparisons, this approach can reveal how flight muscle phenotypes are differentially optimized by age, sex and species to meet and balance identitydependent demands on function. Male birds, for example, have a general tendency in migratory species to arrive earlier to breeding 
grounds in the spring to establish and defend territories (Morbey \& Ydenberg, 2001), which might increase selective pressures to invest resources in flight muscle traits that enhance competitive ability and cold tolerance. Female birds, however, may benefit from maximizing direct investment in reproductive traits, like egg formation, which could potentially draw from protein stores in the pectoralis (Raveling, 1979). If demands on the flight muscle differ between males and females, then we would expect to find associated variation in their flight muscle phenotypes. Similarly, within a sex, social dynamics are often structured by age class, with older individuals being socially dominant (Hawkins, Hill, \& Mercadante, 2012; Lyon \& Montgomerie, 1986; Rohwer, 1982). If older birds are competitively dominant, then we might expect these individuals to have flight muscle traits that enhance competitive ability. Under these hypotheses, we expect to find age- and sex-structured variation in flight muscle phenotypes that reflects the distinct demands on each demographic class.

\section{2 | Muscle response to functional demands}

The diverse functional demands on the pectoralis muscle can be met in part by modifying underlying muscle components, such as muscle fibre composition (Scott et al., 2009). The pectoralis of most volant birds is composed exclusively of the two fast-twitch skeletal muscle fibre types, fast oxidative (FO) fibres and fast glycolytic (FG) fibres, and considerable variation exists across species in the relative abundance of these fibres in the pectoralis (Rosser \& George, 1986; Welch \& Altshuler, 2009). For instance, the pectoralis of small-bodied birds is often exclusively comprised of FO fibres, whereas the pectoralis of larger birds contains a much greater proportion of FG fibres (Rosser \& George, 1986; Welch \& Altshuler, 2009). Only non-volant and soaring species typically incorporate the third main skeletal muscle fibre type, slow oxidative fibres, underscoring the demand on fast-type fibres for powered flight (Meyers \& Stakebake, 2005; Rosser, Waldbillig, Wick, $\&$ Bandman, 1994).

Fibre types differ markedly in their physiological and functional attributes (Peter, Barnard, Edgerton, Gillespie, \& Stempel, 1972), and their relative abundance within the pectoralis should fundamentally impact an individual's capacity for powered flight and thermogenesis. FO fibres are aerobic and can sustain muscle contractions over longer periods of time (Peter et al., 1972). By increasing these fatigue-resistant FO fibres, the pectoralis can enhance functions associated with sustained aerobic performance, like shivering thermogenesis and powered flight. In contrast, FG fibres contain few mitochondria and are primarily anaerobic, but they can generate high mechanical power in short bursts (Peter et al., 1972). FG fibres lack endurance and are not typically recruited during sustained shivering thermogenesis, but are often associated with short-burst flight capacity, like predator avoidance, take-off and other rapid flight maneuvers (Askew, Marsh, \& Ellington, 2001; Dial, Kaplan, Goslow, \& Jenkins, 1987). Through variation in underlying flight muscle fibre composition, species have achieved remarkably diverse ecologies, and while variation in fibre composition within species might also underlie age and sex differences in behaviour and ecology, this remains untested.

\section{3 | Study system: Himalayan bush-robins}

We studied three closely related species of Tarsiger bush-robins (Tarsiger indicus, T. chrysaeus and T. rufilatus) that show species-specific ecologies associated with life along seasonal and elevational gradients in the temperate mountains of Asia. Bush-robins are small passerine birds (12-16 g) that are sexually dichromatic and socially monogamous (Morimoto, Yamaguchi, \& Ueda, 2006). All three species show delayed plumage maturation, in which first-year males (hereafter referred to as subadults) retain female-like plumage despite being fully capable of breeding. Delayed plumage maturation is a widespread, adaptive life-history strategy in which subadult males signal their inferior competitive status to avoid the costs of direct competition against socially dominant adult males (Hawkins et al., 2012). All three species also engage in altitudinal migration, an understudied but widespread behaviour in montane animals (Boyle, 2017; Hsiung, Boyle, Cooper, \& Chandler, 2018). Bush-robin species, however, show striking differences in their winter elevational distributions-the three focal species breed in sympatry above 3,000 $\mathrm{m}$ in the Himalayas and Hengduan mountains of Asia, but migrate downslope to different elevations for winter (Figure 1). Species thus experience different environmental pressures over the course of a year, particularly during harsh montane winters. Furthermore, we show here that each species also exhibits age- and sex-structured differences in the timing of migration, which is another widespread, adaptive life-history strategy in which differences in migratory timing have evolved between sexes and between age classes to optimize lifetime reproduction (Morbey \& Ydenberg, 2001).

We leveraged within- and between-species comparisons in Tarsiger bush-robins, integrating measurements of flight muscle physiology, morphology, behaviour, phenology and environmental data to ask how age- and sex-dependent demands on flight muscle function are reconciled in this essential multifunctional organ. We analyse and interpret flight muscle phenotypes within the context of the three classic life-history strategies described above-sexual dichromatism, delayed plumage maturation, and age- and sex-structured migration (Hawkins et al., 2012; Morbey $\&$ Ydenberg, 2001). This approach provides the necessary framework to interpret our results by evaluating the different selective forces acting on age and sex classes. By extending beyond specieslevel comparisons, we discovered age- and sex-structured variation in flight muscle size and fibre composition that appears to reflect discrete life-history stages and the distinct selective pressures that individuals face as a result of their multi-class identity. Our findings suggest new links between avian physiology, ecology, behaviour and life history, highlighting the importance of ageand sex-dependent selection in shaping functional phenotypic variation. 

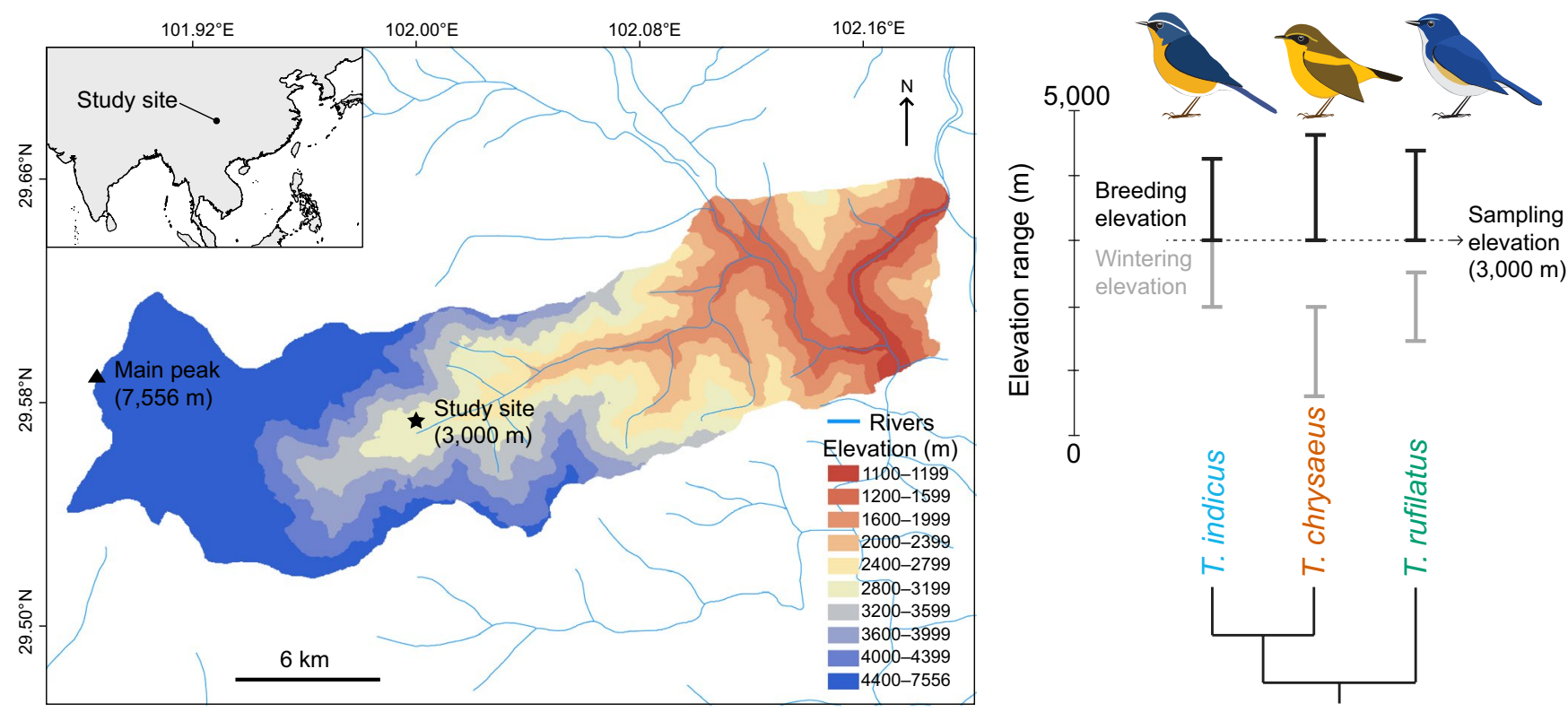

FIGURE 1 Map of Hailuogou Valley, Sichuan, China (study site), phylogenetic relationships and seasonal elevation distributions of study taxa. Phylogenetic relationships are inferred from Sangster et al. (2010), and elevational distributions are from de Hoyo et al. (2005). Birds are shown in definitive adult male plumage

\section{2 | MATERIALS AND METHODS}

\section{1 | Study site, temperature data and sampling}

We caught bush-robins ( $n=329$ ) over three consecutive spring seasons as they migrated upslope to breeding elevations in Hailuogou Valley, Sichuan, China $\left(29.576096^{\circ} \mathrm{N}, 101.998624^{\circ} \mathrm{E}\right)$, on the eastern edge of the Qinghai-Tibet Plateau (Figure 1). In this region, the three species are each other's closest relatives, breeding in sympatry above 3,000 m elevation (Figure 1). Birds were caught at 3,000 m elevation using mist-nets between the dates of 5-22 April 2014, 24-26 March 2015 and 24 March-10 May 2016. On these days, 8-13 twelvemetre mist nets were open from sunup ( $\pm 1 \mathrm{hr}$ ) to sundown ( $\pm 1 \mathrm{hr}$ ). All individuals were caught within $1 \mathrm{~km}$ of a local weather station in a subalpine forest as they moved between elevations (Figure 1), either executing annual spring migration or short-term elevational movements in response to acute early-spring cold weather events. We recorded maximum and minimum temperatures for each individual from the day they were caught, which we collected from the weather station at 3,000 m run by the Institute of Mountain Hazards and Environment, Chinese Academy of Sciences. All individuals used in this study were binned into one of three demographic classes: adult male, subadult male and female. We treated females as a single group because female age classes are indistinguishable by plumage.

Mass was recorded for individuals upon capture, after which birds were either sacrificed for characterization of pectoralis phenotype ( $n=129)$, kept in captivity for other research $(n=36)$, or immediately released back into the environment at 3,000 $\mathrm{m}(n=164)$. In 2014, 11 individuals were target netted, rather than being passively caught. These 11 individuals were thus excluded from arrival time and temperature analyses. Data for each individual can be found in the associated dataset. For all released birds, we uniquely trimmed one to two tail feathers ( $<1 \mathrm{~cm}$ of the tip) to identify if they were recaptured within a given year. For example, one individual might have rectrix right 6 trimmed, while another individual might have right 6 and left 1 trimmed. Bush-robins annually molt tail feathers, so it is unknown if individuals were recaptured across years. However, within a given year, recapture rates were relatively low-only 21 released individuals were caught more than once (over the 3 years: 1 subadult male T. indicus, 1 adult male T. chrysaeus, 3 adult male T. rufilatus, 9 subadult male $T$. rufilatus and 7 female $T$. rufilatus). For individuals that were caught more than once in a year, we report body mass from the day the individual was first caught. We report temperature values, however, from the coldest day an individual was caught (determined from the minimum daily temperature) to specifically test hypotheses associated with cold sensitivity. Because the sex of bush-robins with female-like plumage cannot be determined visually, all released birds with female-like plumage were genetically sexed from blood samples following methods described by Griffiths, Daan, and Dijkstra (1996). All other birds were sexed by examining gonads during dissection. Birds were netted and collected with authorization from Gongga Shan National Nature Reserve and Hailuogou Forestry Bureau in compliance with the National Wildlife Conservation Law of China and birds were handled in accordance with the Institutional Animal Care and Use Committee at the University of Chicago.

\section{2 | Pectoralis mass and histology}

Over the three sampling years, a subset of individuals of each species (T. indicus $n=34, T$. chrysaeus $n=31, T$. rufilatus $n=64$, total $n=129)$ were euthanized using isoflurane anesthesia and thoracic 
compression on the day of capture. For this subset, we measured pectoralis muscle phenotypes. We weighed pectoralis muscles and quantified muscle fibre type. We dissected out the right flight muscle within minutes of each individual being euthanized. The pectoralis major was then separated from the supracoracoideus and the entire right pectoralis was weighed. We report total organism pectoralis mass as the right pectoralis multiplied by two. We then dissected out the middle third of the right pectoralis (in relation to the length of the keel), coating this muscle section in O.C.T. embedding medium, which was then flash-frozen in liquid nitrogen-cooled isopentane. Embedded muscle was then sealed in aluminum foil and stored in liquid nitrogen until being transferred into $\mathrm{a}-80^{\circ} \mathrm{C}$ freezer, where they were stored until being sectioned.

Muscle fibre types were characterized in the pectoralis using methods described by Deveci, Marshall, and Egginton (2001). Pectoralis muscles were sectioned $(10 \mu \mathrm{m})$ in a cryostat at $-20^{\circ} \mathrm{C}$, transverse to the length of the muscle fibres. Sections were then stained for myosin-ATPase (preincubation at $\mathrm{pH} 4.4$ ) and succinate dehydrogenase (SDH) activity to distinguish muscle fibre types (Deveci et al., 2001). We imaged the stained sections with a light microscope and used stereological methods described by Egginton (1990) to make unbiased measurements of numerical fibre density, areal fibre density, and average transverse area of each fibre type. For each sample, we analysed 12 images to account for fibre heterogeneity within the muscle, which we determined in preliminary measurements to be a sufficient number of images to achieve a stable mean value for an individual bird. The mean areal densities of each fibre type were used as an estimate of the proportion of muscle volume composed of that fibre type. This approach allowed us to multiply mean areal density by pectoralis mass to calculate the total mass of each fibre type in the pectoralis for each individual. This calculation assumes that each fibre type had the same tissue density (mass per volume), and therefore ignores the small potential differences in tissue density that could arise from differences in lipid content between fibre types. However, intracellular lipid volume density differs by $<5 \%$ between FO and FG fibres in bird flight muscle (Scott et al., 2009), so the differences in tissue density between fibre types may be even smaller. Fibre type was preferentially assessed using myosin-ATPase stained sections unless these sections were unavailable (due to tissue damage during staining procedure). In these cases, we quantified fibre type from SDH stained sections. We confirmed that fibre-typing outcomes were consistent between the two staining methods by comparing a subset of individuals in which both staining methods were analysed (Figure S1).

\section{3 | Vouchered specimens and morphometric measurements}

All birds collected for pectoralis phenotyping are vouchered as specimens at the National Zoological Museum of the Institute of Zoology (Chinese Academy of Sciences) or at the Nature Museum of Sichuan University, except for five individuals that were stolen by a Siberian weasel (Mustela sibirica) at our study site in 2015. The list of vouchered specimens can be found in the associated dataset. With these specimens, we measured tarsus length and Kipp's index as proxies for ecological differences among species (Kipp, 1959). Tarsus length and Kipp's index (i.e. wing shape) are standard morphological measurements that are strongly linked to ecology (Lockwood, Swaddle, \& Rayner, 1998). We report Kipp's index on a size-independent scale (0-1) from short, rounded wings to long narrow wings (Kipp, 1959). Kipp's index was calculated as: (length of longest primary featherlength of first secondary feather)/length of longest primary feather.

\subsection{Statistical analyses}

We tested for statistical differences among species, between sexes and between male age classes with analysis of variance tests. We report means and standard errors for each trait by species, age and sex class. We analysed all flight muscle traits (i.e. pectoralis mass, FG fibre mass and FO fibre mass) as raw values and relative values (calculated as mass of the given trait divided by body mass), but the interpretations of results remain the same with and without controlling for differences in body mass. We tested for differences among species in each trait using ANOVAs (type III sums of squares) with accounting for class identity (i.e. adult male, subadult male, female) and year $(2014,2015,2016)$ as additional predictor variables. We then performed a Tukey's post-hoc test to determine which pairwise species comparisons differed significantly for each trait. Within each species, we then tested for sex differences in each trait with ANOVAs (type III sums of squares), accounting for year as a predictor variable. For these analyses, adult males and subadult males were analysed together relative to females. Analyses of sex differences were conducted for each species independently. We then tested for age differences in males for each trait with ANOVAs (type III sums of squares), also accounting for year as a predictor variable. Analyses of age differences were conducted for each species independently. Differences were treated as significant if $p<0.05$, and effect sizes were calculated from ANOVAs as partial eta squared $\left(\eta^{2}\right)$.

\section{3 | RESULTS}

\subsection{Variation in flight muscle phenotype}

Pectoralis mass and body mass varied foremost by species and sex class-pectoralis muscles and body mass were larger in T. indicus and $T$. rufilatus than in $T$. chrysaeus, and larger in males than in females (Figure 2; Tables 1 and 2). Despite the small body size of bush-robins (12-16 g), we discovered the presence of both fast-type muscle fibres (FO and FG) in the pectoralis of all three species (a representative image of a bush-robin pectoralis with mixed fibre types can be seen in Figure 3). We found no evidence of slow oxidative fibres in the pectoralis of bush-robins. The relative proportions of FO and FG fibres that we observed within the pectoralis of bushrobins varied consistently within species by age and sex (Figure 4). 
FIGURE 2 Pectoralis muscle mass plotted against body mass. Left panel shows species means (with standard error bars), plotted by age and sex classes $(n=129)$. Species are plotted by colour (Tarsiger indicus = blue, Tarsiger chrysaeus = red, Tarsiger rufilatus = green). Right panels are broken down by species to show values for each individual. Sample sizes for body mass and pectoralis mass can be found in Table 2 for females and in Table 3 for male age classes
TABLE 1 Species differences in body mass, flight muscle phenotypes, experienced temperature and arrival time, analysed with an (ANOVA, type III sums of squares) with accounting for class identity (i.e. adult male, subadult male, female) and the year an individual was caught in the model as additional predictor variables. Means, standard errors and sample sizes for each trait are reported for each species. Comparisons were performed using Tukey's post-hoc tests for each trait. Superscript letters denote pairwise statistical differences for a given trait in which species with different letters are significantly different at $p<0.05$, while species with similar letters are not statistically different from one another. The effect size of 'species' is reported as partial eta squared $\left(\eta^{2}\right)$ for each trait. 'FO', fast oxidative; 'FG', fast glycolytic; 'raw', mass of the specified trait uncorrected for body mass; 'relative', mass of the specified trait analysed as a proportion of body mass
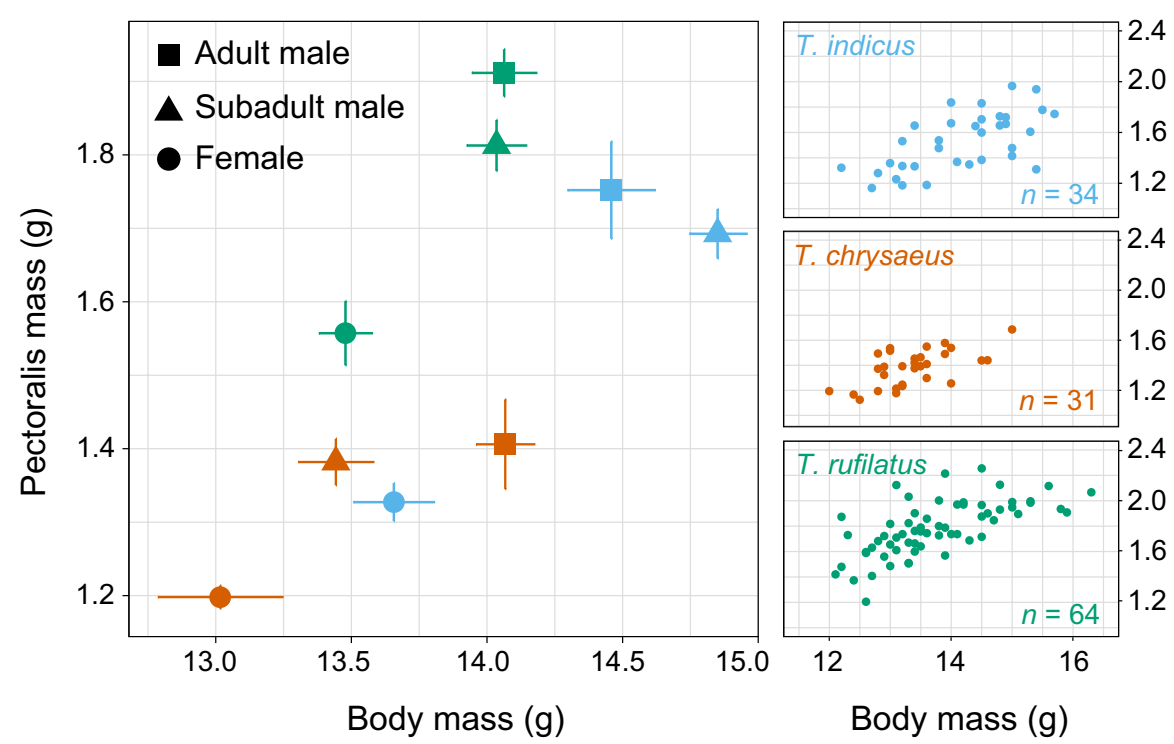

\begin{tabular}{|c|c|c|c|c|}
\hline Trait & Tarsiger indicus & Tarsiger chrysaeus & Tarsiger rufilatus & $\eta^{2}$ \\
\hline Body mass (g) & $14.26 \pm 0.10^{\mathrm{A}}$ & $13.81 \pm 0.09^{\mathrm{B}}$ & $13.83 \pm 0.06^{B}$ & 0.10 \\
\hline$N$ & 69 & 76 & 181 & \\
\hline Pectoralis mass (g, raw) & $1.53 \pm 0.03^{\mathrm{A}}$ & $1.37 \pm 0.02^{\mathrm{B}}$ & $1.79 \pm 0.01^{C}$ & 0.60 \\
\hline$N$ & 34 & 31 & 64 & \\
\hline Pectoralis mass (\%, relative) & $10.77 \pm 0.15^{\mathrm{A}}$ & $10.31 \pm 0.10^{B}$ & $12.95 \pm 0.08^{C}$ & 0.64 \\
\hline$N$ & 34 & 30 & 63 & \\
\hline FO fibre mass (g, raw) & $1.26 \pm 0.02^{A}$ & $1.27 \pm 0.01^{\mathrm{A}}$ & $1.51 \pm 0.01^{\mathrm{B}}$ & 0.42 \\
\hline$N$ & 29 & 26 & 56 & \\
\hline FO fibre mass (\%, relative) & $8.83 \pm 0.11^{\mathrm{A}}$ & $9.53 \pm 0.10^{A}$ & $10.99 \pm 0.07^{B}$ & 0.50 \\
\hline$N$ & 29 & 26 & 55 & \\
\hline FG fibre mass (g, raw) & $0.30 \pm 0.02^{A}$ & $0.10 \pm 0.01^{B}$ & $0.29 \pm 0.01^{\mathrm{A}}$ & 0.45 \\
\hline$N$ & 29 & 26 & 56 & \\
\hline FG fibre mass (\%, relative) & $2.08 \pm 0.13^{A}$ & $0.76 \pm 0.07^{B}$ & $2.04 \pm 0.05^{\mathrm{B}}$ & 0.45 \\
\hline$N$ & 29 & 26 & 55 & \\
\hline $\begin{array}{l}\text { Maximum daily } \\
\text { temperature }(\mathrm{C})\end{array}$ & $9.03 \pm 0.52^{A}$ & $11.46 \pm 0.67^{B}$ & $9.61 \pm 0.32^{A}$ & 0.09 \\
\hline$N$ & 65 & 71 & 182 & \\
\hline $\begin{array}{l}\text { Minimum daily } \\
\text { temperature (C) }\end{array}$ & $0.22 \pm 0.24^{\mathrm{A}}$ & $1.54 \pm 0.25^{\mathrm{B}}$ & $1.06 \pm 0.14^{B}$ & 0.11 \\
\hline$N$ & 65 & 71 & 182 & \\
\hline Arrival date (Julian date) & $102.46 \pm 1.07^{A}$ & $113.08 \pm 0.73^{B}$ & $107.72 \pm 0.54^{c}$ & 0.21 \\
\hline$N$ & 65 & 71 & 182 & \\
\hline
\end{tabular}

This intraspecific variation was greater within species than has been previously described between species under $20 \mathrm{~g}$ (Lundgren \& Kiessling, 1988; Rosser \& George, 1986).

When we considered the relative contributions of each fibre type to total pectoralis mass, the total masses of both FO fibres and FG fibres-calculated as the product of muscle mass and the areal density of each fibre type-were larger in males than females (Figure 4; Table 2; see Figure S2 for areal density, numerical density and average traverse area for FG and FO fibres by species, age and sex class, as well as average fibre size, which combines FG and FO fibres). FO fibre mass did not differ between male age classes, but FG fibre masses were consistently larger in adult males than subadult males (Figure 4; Table 3), reflecting increased investment by adult males in FG fibres. Among species, T. rufilatus had the largest FO fibre mass (Figure 4a,b), which is consistent with a more flighted ecology as suggested by its longer wings and shorter legs (Figure S3; Lockwood et al., 1998). Tarsiger indicus and T. chrysaeus, however, have similar wing shapes and tarsus lengths (Figure S3), and had 


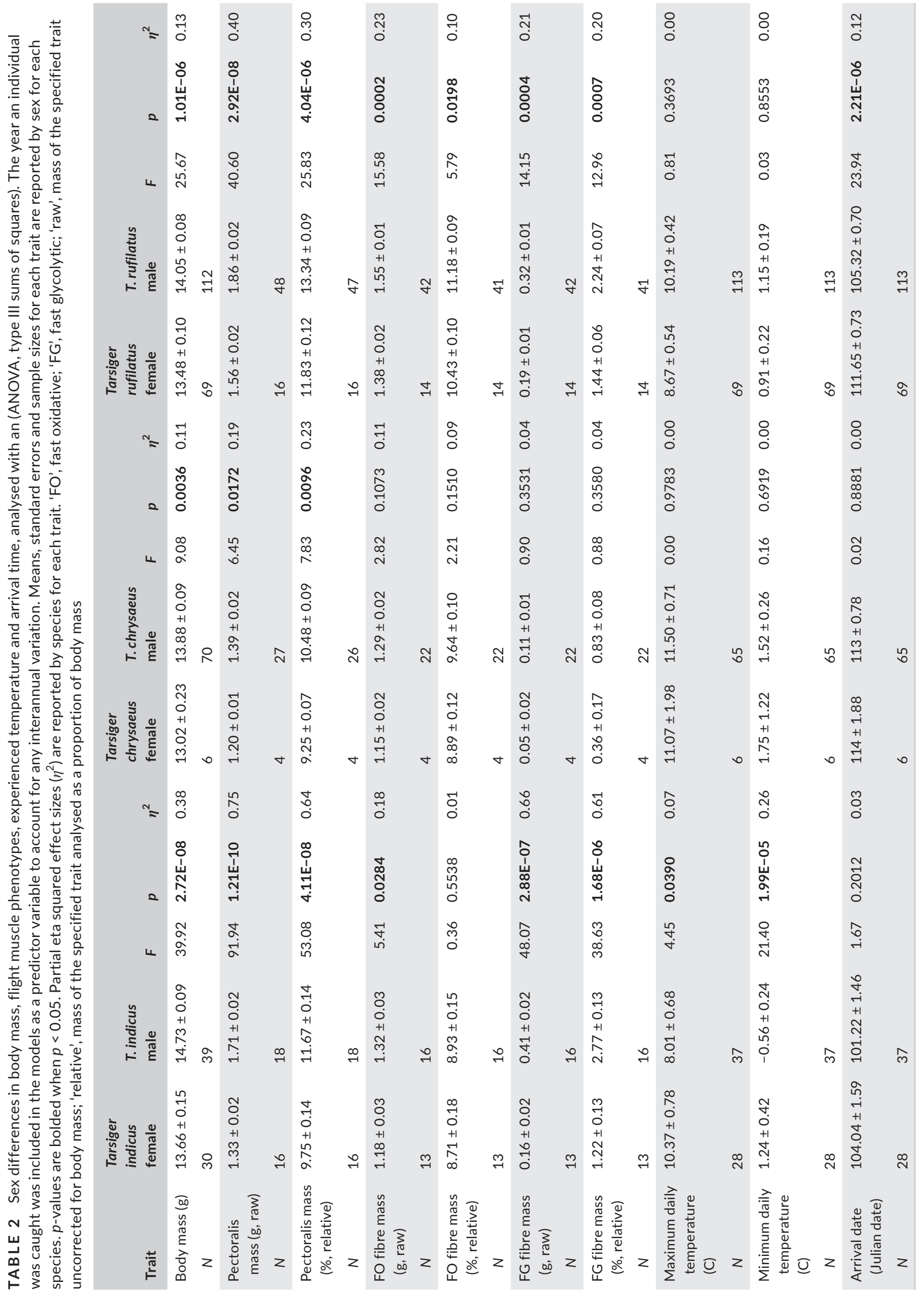


FG and FO fibres

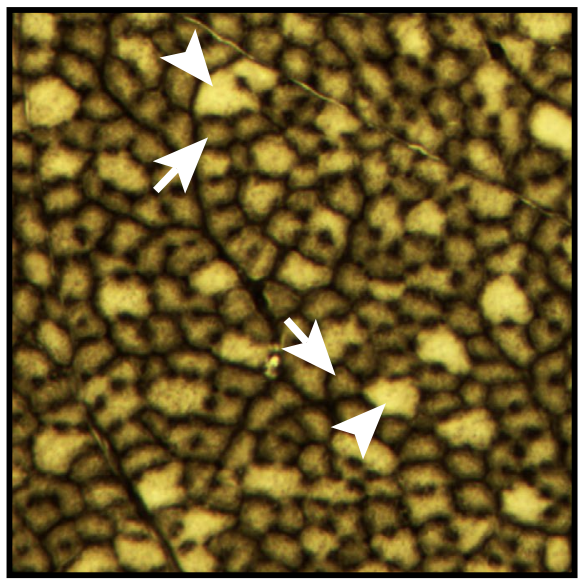

FO fibres only

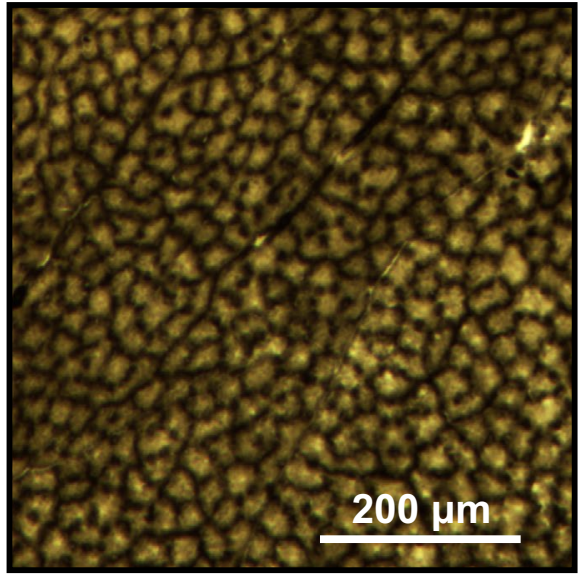

FIGURE 3 Histochemical staining of bush-robin pectoralis muscle. Representative cross-sections of individuals with mixed fibre types, both fast glycolytic (FG) fibres and fast oxidative (FO) fibres (left panel), or only fast oxidative (FO) fibres (right panel). Cross-sections are from two female Tarsiger rufilatus that show considerable differences in pectoralis fibre composition. Muscles were stained with myosinATPase to identify fibre types. Arrowheads point to examples of FG fibres, and arrows point to examples of FO fibres. The pectoralis crosssection in the right image is composed of only FO fibres

$-T$. indicus $-T$. chrysaeus $-T$. rufilatus

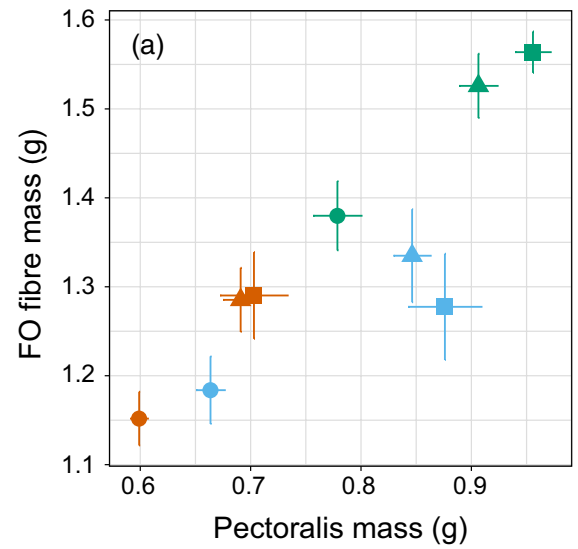

Adult male $\triangle$ Subadult male Female

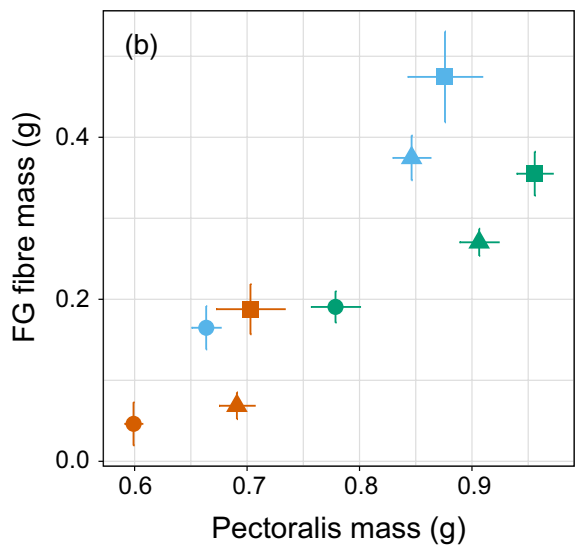

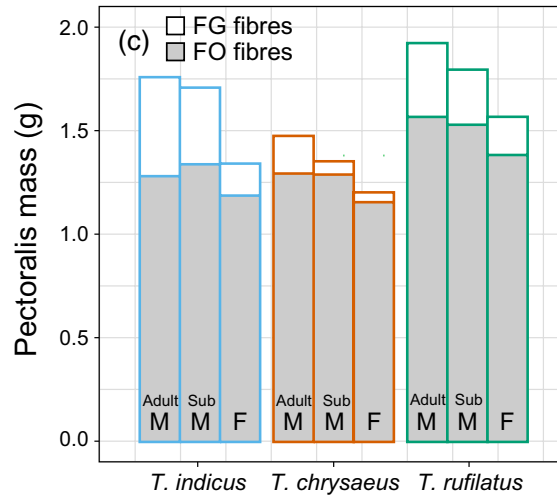

FIGURE 4 The relative contributions of fast oxidative (FO) fibre mass and fast glycolytic (FG) fibre mass to overall pectoralis mass. Panels (a) and (b) show species means (with standard error bars), plotted by age and sex classes. Species are plotted by colour. Panel (c) shows the ratio of each fibre type by age and sex class within each species (the mean of each fibre type was used). "Adult M" are adult males, "Sub M" are subadult males, and "F" are females. Sample sizes for pectoralis mass and fibre masses can be found in Table 2 for females and in Table 3 for male age classes

strikingly similar FO fibre mass, despite $T$. indicus having larger pectoralis muscles (Figure 4a,c; Table 1). The differences in pectoralis mass between $T$. indicus and $T$. chrysaeus reflect increases in FG fibres in $T$. indicus, rather than changes in FO fibre mass.

\subsection{Variation in timing of arrival to breeding elevations}

Bush-robins differed within and among species in their timing of migration to breeding elevations. Arrival order among species was associated with wintering elevation and seasonal temperaturespecies that wintered higher arrived earlier to breeding elevations
(Figure 5a; Figure S4), and birds that arrived earlier experienced colder temperatures (Figure 5b; Figure S5; Tables 1-3). Tarsiger indicus arrived first, followed by T. rufilatus and then T. chrysaeus. Within each species, we observed the same qualitative patterns of age- and sex-structured migration, in which adult males arrived before subadult males, which in turn arrived before females (Figure $5 \mathrm{~b}$ ). The one exception to this pattern is with T. chrysaeus females, which arrived between adult and subadult males. This exception might reflect low sample sizes for this group or terminating sampling before the completion of female migration for T. chrysaeus. In each sampling year, some males of $T$. indicus were already singing above 3,000 $\mathrm{m}$ on the breeding grounds when we began sampling, indicating that these individuals had already passed through our 


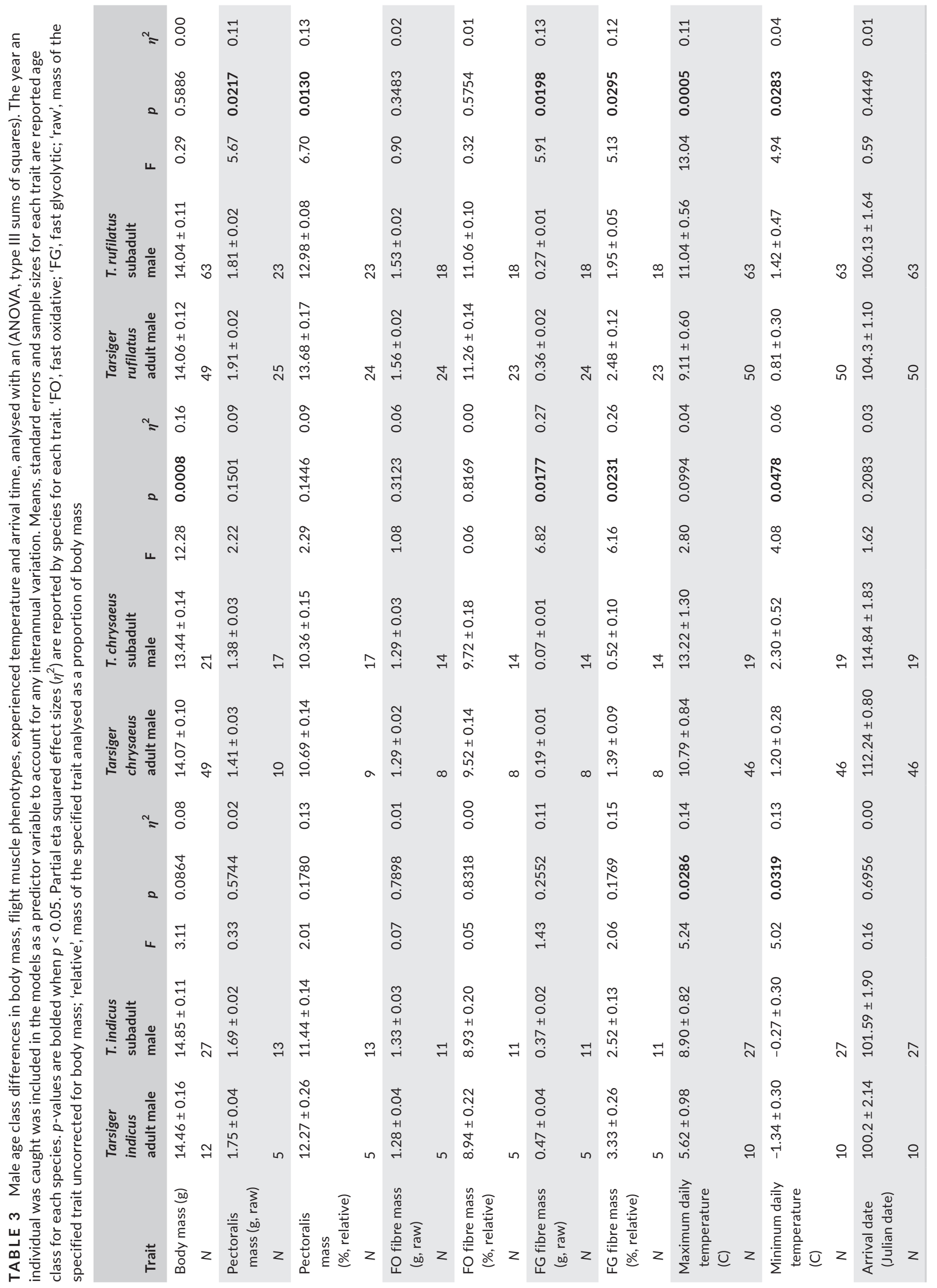



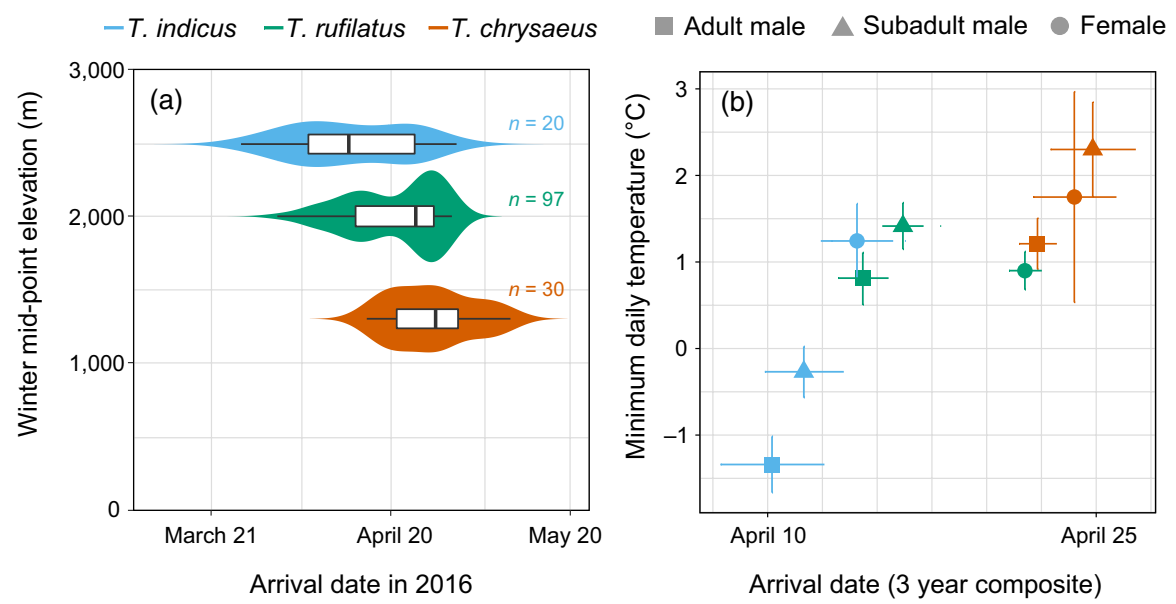

FIGURE 5 Individuals of Tarsiger species that winter higher arrived first to breeding elevations, when temperatures were coldest. (a) The mid-point of species' wintering elevations plotted against arrival date to 3,000 m elevation in 2016 . Plots for 2014 and 2015 can be found in Figure S4. Box plots show median date and quartiles of arrival data. Violin plots show the distributions of arrival. (b) Minimum daily temperature on the day each individual was caught, averaged over the three sampling years. Species means (with standard error bars) are plotted by age and sex class. Sample sizes for minimum daily temperature and arrival date (3-year composite) can be found in Table 2 for females and in Table 3 for male age classes
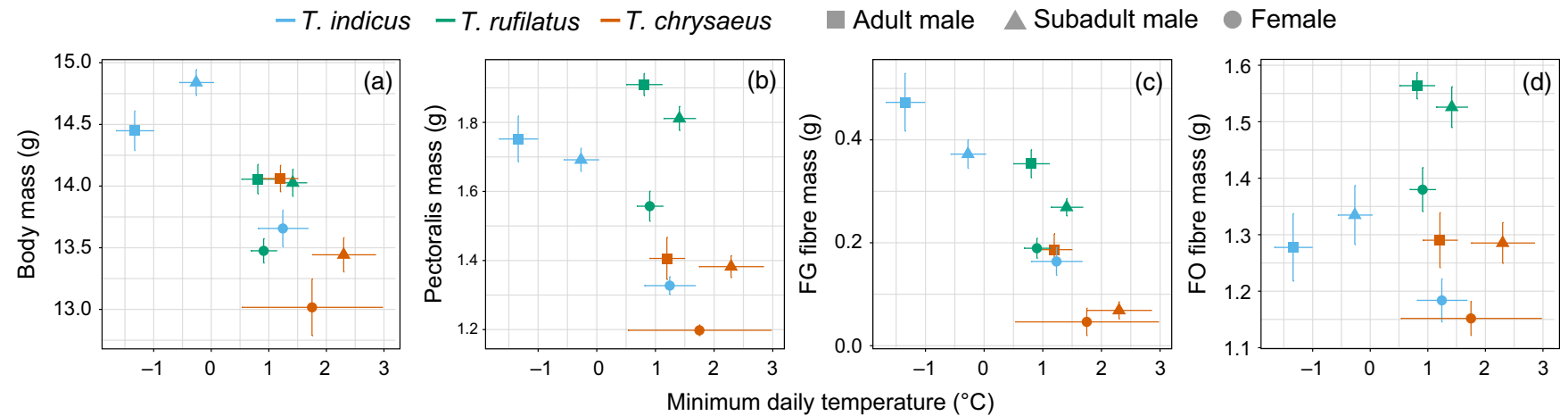

FIGURE 6 Mass and pectoralis phenotypes plotted against minimum daily temperature on the day each individual was caught. Species means (with standard error bars) are plotted by age and sex classes. Species are plotted by colour. Panels (c) and (d) plot the fibre-specific masses of the pectoralis. Sample sizes for (a) body mass, (b) pectoralis mass and (c, d) fibre masses can be found in Table 2 for females and in Table 3 for male age classes

sampling area. This observation implies that we are conservatively estimating the arrival time of $T$. indicus males as well as the disparity in arrival time and experienced temperature between $T$. indicus age and sex classes.

\subsection{Association of flight muscle phenotypes with arrival and seasonal temperature}

Species, age and sex classes caught earlier in spring, when temperatures were colder, generally had larger body mass, as well as larger raw and relative pectoralis masses (Figure 6a,b; Figures S6a and S7a,b,e; Tables 1-3). The association between pectoralis mass and temperature appears to be driven by differences in FG fibre mass among and within species. That is, species, age and sex classes that were caught earlier, when temperatures were colder, have increased FG fibre mass in their pectoralis (Figure 6c; Figures S6b and
S7c,f). This result is counterintuitive, as the other fibre type (FO fibres) is believed to contribute to the majority of sustained thermogenesis, while FG fibres contribute little (Marsh \& Dawson, 1989), yet individuals that experience colder temperatures are investing resources in FG fibres, which could be otherwise invested in FO fibres. The larger FO fibre mass in males than females was generally associated with earlier arrival and colder temperatures, but differences among species in FO fibre mass were not (Figure 6d; Figures S6c and S7d,g).

\subsection{Variation in sensitivity to cold stress and extreme weather events}

We found that bush-robins vacate breeding territories in response to acute cold weather events in early spring. In response to these events, bush-robins shifted downslope or halted migration upslope, 
returning to breeding elevations as soon as temperatures warmed, even when snow still covered the ground (Figure S8). The propensity for birds to vacate breeding elevations, however, varied by species, age and sex in association with wintering elevation and arrival order. That is, species that winter higher were more likely to persist at breeding elevations through acute cold weather events, as were adult males (Figure S8). This behavioural flexibility confounds and introduces noise into our arrival time data because not all captures at 3,000 $\mathrm{m}$ reflect an individual's first arrival for the given season. Nevertheless, despite these events, we recovered species-, age- and sex-structured differences in occurrence patterns at 3,000 m elevation (the lower elevational breeding limit) that are associated with wintering elevations and temperature.

\section{4 | DISCUSSION}

\section{1 | Evidence for a new ecological context of fast glycolytic fibres}

The discovery of mixed fibre types in the pectoralis of bush-robins is striking given their small body size (12-16 g) because the pectoralis of most birds under $20 \mathrm{~g}$ had previously been found to contain only FO fibres (Rosser \& George, 1986; Welch \& Altshuler, 2009). Given that FO fibres alone are sufficient to meet all functional demands on the pectoralis in other small-bodied birds (Dakin et al., 2018; Welch $\&$ Altshuler, 2009), the presence of mixed fibres in bush-robins suggests a new functional context for FG fibres. In larger birds, FG fibres are essential for short but high intensity bursts of muscle contraction, like those needed for take-off, because high mechanical power is required to lift larger birds into the air (Dial et al., 1987). Smaller birds, however, are less constrained by mass-specific demands on fibre type for take-off, and FO fibres are generally thought to meet all of their functional demands of powered flight (Welch \& Altshuler, 2009). To date, FG fibres have been observed in the pectoralis of only two other species under $20 \mathrm{~g}$, the Ovenbird (Seiurus aurocapilla, Rosser \& George, 1986) and the European Robin (Erithacus rubecula, Lundgren \& Kiessling, 1988), a close relative of Tarsiger bush-robins (Sangster Alström, Forsmark, \& Olsson, 2010). It is possible, however, that these fibres may be more taxonomically widespread since fibre composition has been characterized in less than $5 \%$ of bird species (which we estimated from a literature search).

If FG fibres are not necessary for take-off in small birds, then their presence in robins might be associated with alternative forms of high-intensity flight, such as burst flights associated with competitive interactions and/or predator avoidance. The high mechanical power of FG fibres should enhance short-burst flight capacity, improving for example an individual's ability to secure and defend breeding territories and mates (Altshuler, 2005). Under this hypothesis, we would expect to find increases in FG fibres in socially dominant individuals, which we found support for in all three bush-robin species (Figure 4b). Males had more FG fibres than females, and adult males had more FG fibres than subadult males. Alternatively, in sexually dichromatic species, like bush-robins, adult males might experience increased predation risk due to bright, conspicuous plumage or reduced vigilance during competitive interactions (Götmark, 1993; Jakobsson, Brick, \& Kullberg, 1995). Under this hypothesis, adult males would benefit from FG fibres and the associated increases in short-burst flight capacity to avoid predation. These two hypotheses (i.e. competition and predation) are not mutually exclusive, but require further testing to tease apart. Nevertheless, the presence of FG fibres in bush-robins represents a unique functional context in which variation in muscle phenotypes in small birds appears to be tied to life-history trade-offs and social demands.

\section{2 | Sex-dependent selection on flight muscle phenotype}

We found that male bush-robins generally arrived to breeding grounds before females (Figure $5 \mathrm{~b}$ ), which is a common migratory strategy in birds (Morbey \& Ydenberg, 2001). This life-history strategy is assumed to arise through sex-dependent selection that increases reproductive success in one or both sexes (Morbey \& Ydenberg, 2001). A number of hypotheses have been proposed to explain the adaptive significance of sex-structured migration. For example, territorial males may be under selection to arrive earlier to breeding grounds to establish territories (Myers, 1981). This hypothesis is supported by a preponderance of work showing early-arriving males achieve higher reproductive success (Lozano, Perreault, \& Lemon, 1996; Perrins, 1970). In addition, females may be under stronger selection to arrive later to avoid unfavourable environmental conditions in early spring (Ketterson \& Nolan, 1983). This hypothesis is particularly notable in our temperate, high-elevation context because female bush-robins should disproportionately benefit from investing resources directly into reproductive traits, such as egg formation, rather than investing in muscle changes that enhance cold tolerance (Wedell, Kvarnemo, \& Tregenza, 2006). Although the fitness consequences of sex-structured migration in bush-robins remain unknown, this adaptive life-history strategy exposes males and females to different environmental and social pressures (Figure 5b). Male bush-robins should thus benefit from morphological and physiological traits that enhance thermogenic capacity and competitive ability, like increases in both FO and FG fibres, facilitating early arrival and territoriality, while females should benefit from later arrival to breeding grounds when conditions are more favourable, allowing them to maximize direct investment in reproductive traits, like gametes and parental care (Wedell et al., 2006). Despite a conservative estimate of male arrival for T. indicus (due to the fact that males were already singing at breeding elevation when we began sampling), we still recovered signals of sex- and age-structured variation in experienced temperature.

The variation we observed between sexes in flight muscle phenotypes is consistent with the sex-dependent selection associated with sex-structured migration. Compared to females, male bush-robins showed increases in the total mass of 
fatigue-resistant FO fibres in the pectoralis, which is expected to enhance the capacity for shivering thermogenesis (Petit \& Vézina, 2014; Swanson, Zhang, \& King, 2013). Males also showed greater total mass of the more powerful FG fibres, which should enhance short-burst flight capacity, which supports the hypothesis that FG fibres may play a role in social dynamics and competitive interactions in bush-robins. Increases in both muscle fibre types appear to have evolved in association with environmental and social demands on males, suggesting that functional trade-offs at the fibre level might be overcome by making the whole flight muscle bigger. In contrast, females show reduced investment in the pectoralis in association with their later arrival to breeding elevations. This reduced investment was generally associated with reduced investment in both fibre types (Figure 4), but the lower proportional abundance of FG fibres in females (Figure S2) suggests that females reduce investment in this fibre type by a greater magnitude. By arriving when spring temperatures are warmer, and after males have established territories, females should experience reduced pressure to allocate resources into flight muscles that increase cold tolerance and competitive traits. Instead, females can invest resources in reproductive traits outside of the flight muscle. These results underscore how the tensions shaping flight muscle phenotypes, and functional optima, differ between sexes.

\subsection{Age differences in social dominance and flight muscle phenotype}

The variation in FG fibre mass between male age classes further supports the hypothesis that FG fibres are important in social dynamics and competitive interactions. Adult males showed increased FG fibre mass compared to subadult males (Figure 4b), and given what we know about the physiological and functional differences between muscle fibre types (Peter et al., 1972), this age-structured variation in muscle morphology should contribute to greater competitive abilities in adult males. If males are under selection to arrive early to secure breeding territories, then traits that enhance territory defence and competitive ability, like FG fibres, should also be under selection to increase. The lower number of FG fibres in subadult males likely contributes to their reduced competitive ability, which is further supported by their migratory behaviour and plumage phenotype. If subadult males are competitively inferior to adult males because they have less capacity for burst muscle performance (i.e. they have fewer FG fibres), then subadult males should benefit from avoiding costly interactions, like fighting, with dominant males. Subadult males appear to avoid these costly interactions by arriving later to breeding elevations, and by retaining female-like plumage through delayed plumage maturation. The lifehistory strategy of delayed plumage maturation allows subadult males to honestly and effectively signal their inferior competitive ability to avoid costly aggressive interactions (Hawkins et al., 2012).

Our results imply that it is not only experience in breeding and fighting that makes subadult males inferior (Arcese \& Smith, 1985), but that they have invested less in various flight muscle traits, which may render them less competitively able than their adult counterparts. At this time, the proximate causes of this reduced investment in FG fibres are unknown, but in subadult males, they may simply need more time to grow and develop the phenotype typical of adult males. The proximate causes might also include carryover effects from winter in which traits that impact breeding success, such as body condition or the timing of migration, are linked to wintering habitat quality (Harrison, Blount, Inger, Norris, \& Bearhop, 2011; Studds \& Marra, 2005). If subadult-male bush-robins occupy lower quality wintering habitats, this would likely have downstream consequences on their ability to allocate resources to competitive traits, such as FG fibres. Irrespective of the potential causes, however, our findings provide some of the first evidence to suggest that variation in functional traits might be associated with delayed plumage maturation and the competitive inferiority of subadult males.

\subsection{Species differences in ecology and flight muscle phenotype}

We found that species that arrive earlier in spring have larger pectoralis muscles than later arrivals, which is consistent with past work showing that cold tolerance increases with flight muscle size (Petit \& Vézina, 2014; Swanson et al., 2013). The relationship between flight muscle mass and cold tolerance, however, has been previously defined in species whose pectoralis muscles contain only FO fibres (e.g. the American Goldfinch [Spinus tristis] and Blackcapped Chickadee [Poecile atricapillus]; Petit \& Vézina, 2014; Rosser \& George, 1986; Swanson et al., 2013). In bush-robins, when we consider the relative contributions of fibre type to overall pectoralis mass and function, $T$. indicus and T. chrysaeus have strikingly similar FO fibre mass (Figure 4a,c), despite experiencing dramatically different thermal environments in a given year. The differences in pectoralis mass between $T$. indicus and T. chrysaeus are thus not due to changes in FO fibre mass, but rather differences in FG fibre mass. The predominant expectation is that FG fibres could contribute to short bursts of high intensity shivering, supported by anaerobic metabolism, but the low mitochondrial content of FG fibres makes them unlikely to contribute to long periods of sustained thermogenesis (Marsh \& Dawson, 1989). These results underscore the need to account for fibre-type variation when interpreting differences in flight muscle size, while also highlighting the need to better understand the phylogenetic extent of mixed fibres in the pectoralis.

Among species, the staggered pattern of migration suggests a connection between seasonal distributions, migratory distance, phenological events and cold tolerance. These data suggest that T. indicus is more cold tolerant than T. rufilatus, which is more cold tolerant than T. chrysaeus. Under thermogenic predictions alone, we would expect $T$. indicus to have pectoralis phenotypes that confer adaptive increases in cold tolerance, such as increases in the mass of FO fibres. Tarsiger rufilatus, however, had the highest FO fibre mass. This discrepancy can be reconciled when we consider 
species-specific ecology, migratory distance and that a system of interconnected traits within the flight muscle and organism work in concert to define whole-organism metabolism and capacities for thermogenic and locomotory performance (McClelland \& Scott, 2019; Storz \& Scott, 2019). First, T. rufilatus appears to have a more flighted ecology than the other two species, as suggested by morphometric data (Figure S3), which might drive increased FO fibre mass in T. rufilatus. Tarsiger rufilatus and T. chrysaeus also migrate further than $T$. indicus, which may require higher proportional FO fibre content to aid in these seasonal movements (Dawson, Marsh, \& Yacoe, 1983; Figure S2). This FO fibre requirement may be especially true for $T$. chrysaeus, which migrates the furthest despite being the least flighted and most terrestrial (as inferred from wing and leg data; Figure S3; de Hoyo, Elliott, Sargatal, Christie, \& de Juana, 2005).

The predicted differences in cold tolerance between species might be achieved through variation in other traits that work synergistically with muscle fibres to impact metabolism and heat loss at upper elevations. Given that high-elevation environments are hypoxic, species differences in thermogenic capacity could arise from variation in the ability to supply oxygen to muscle mitochondria, independent of the variation in muscle size and fibre composition (McClelland \& Scott, 2019; Storz \& Scott, 2019). The mechanisms underlying such differences could include variation in haemoglobin oxygen-binding affinity and muscle oxygen diffusion (Zhu et al., 2018), enzyme activity in metabolic pathways (Stager, Swanson, \& Cheviron, 2015), and the position of mitochondria within muscle fibres (Scott et al., 2009). Species differences in cold tolerance could also result from variation in feather insulation (Herreid \& Kessel, 1967). Variation in these other traits might compensate for variation in fibre-type composition that does not serve to improve cold tolerance, allowing fibre type to evolve along other functional axes. Modifications in these other traits could also vary within species along demographic axes, thus offering promising directions for future research.

\section{CONCLUSIONS}

By integrating temperature data with physiological and behavioural data across demographic axes, we discovered age- and sexstructured variation in flight muscle phenotypes that is associated with discrete life-history stages. This functional variation can be understood within a context of the selective pressures imposed on each demographic class. By analysing flight muscle phenotypes within the context of well-studied, adaptive life-history strategies, like sexual dichromatism, age- and sex-structured migration, and delayed plumage maturation, we can better understand the selective environments under which variation in flight muscle phenotypes arises and is maintained, which in turn provides insight into the mechanisms underlying these life-history strategies. While it is unclear at the moment whether the observed phenotypic variation is genetic, environmentally induced, or seasonally plastic, this variation should nevertheless have downstream consequences on muscle performance across age and sex classes. Our findings demonstrate how flight muscle phenotypes are shaped at the nexus of life history and multi-class identity (i.e. species, age and sex), highlighting the importance of intraspecific selection in shaping functional phenotypic variation within animal populations.

\section{ACKNOWLEDGEMENTS}

We thank the staff of the Department of Forestry of Sichuan Province, Gongga Shan National Nature Reserve and Hailuoguo Forestry Bureau, specifically Xiaodong Gu, Huaming Zhou, Yugang Li, Shaojun Mao, Qiang Xie and Tianzhen Ni. Bird illustrations in Figure 1 are by Daniela Palmer. This work was supported by grants to S.G.D. from the National Geographic Society/Waitt Fund, the American Philosophical Society, the American Museum of Natural History, the American Ornithological Society, the Society for the Study of Evolution, the Paulson Institute, the Field Museum's H. B. Conover Fund and the Animal Behavior Society; by grants to Y.W. from the National Natural Science Foundation of China (31501851) and the International Visiting Program for Excellent Young Scholars of Sichuan University; and by grants to F.L. from the Strategic Priority Research Program, Chinese Academy of Sciences (XDB13020300) and the State Key Program of NSFC (31630069). We thank Jake Allgeier, Susanna Campbell, Yalin Cheng, Katie Collins, Stewart Edie, Valentina Gómez-Bahamón, Eric Gulson-Castillo, David Jablonski, Dallas Krentzel, Marcus Kronforst, Daniela Palmer, Teresa Pegan, Trevor Price, Mariah Scott, Gang Song, Tom Stewart, Supriya, David Swanson, Alex White, Brian Weeks, Benjamin Winger and Xiaojia Zhu for their support and thoughtful comments on previous versions of this manuscript. We also thank four anonymous reviewers for comments that improved this manuscript.

\section{AUTHORS' CONTRIBUTIONS}

S.G.D., Y.W., G.R.S, Y.Q., Z.A.C., F.L. and J.B. designed research; S.G.D., Y.W., J.H.S., C.X., A.H.R., C.J., D.M. and J.W. performed research; S.G.D. and J.J. analysed data; Y.W. and Q.L. coordinated data provision; S.G.D. wrote the paper.

\section{DATA AVAILABILITY STATEMENT}

Data for this article are deposited on Dryad Digital Repository: https://doi.org/10.5061/dryad.jsxksn05s (DuBay et al., 2020)

\section{ORCID}

Shane G. DuBay (iD https://orcid.org/0000-0002-7221-7546

Fumin Lei (iD https://orcid.org/0000-0001-9920-8167

\section{REFERENCES}

Altshuler, D. L. (2005). Flight performance and competitive displacement of hummingbirds across elevational gradients. The American Naturalist, 167(2), 216-229. https://doi.org/10.1086/498622

Arcese, P., \& Smith, J. N. M. (1985). Phenotypic correlates and ecological consequences of dominance in song sparrows. Journal of Animal Ecology, 54(3), 817-830. https://doi.org/10.2307/4380

Askew, G. N., Marsh, R. L., \& Ellington, C. P. (2001). The mechanical power output of the flight muscles of blue-breasted quail (Coturnix 
chinensis) during take-off. Journal of Experimental Biology, 204(21), 3601-3619.

Biewener, A. A., Dial, K. P., \& Goslow, G. E. (1992). Pectoralis muscle force and power output during flight in the starling. Journal of Experimental Biology, 164(1), 1-18.

Bolnick, D. I., Amarasekare, P., Araújo, M. S., Bürger, R., Levine, J. M., Novak, M., ... Vasseur, D. A. (2011). Why intraspecific trait variation matters in community ecology. Trends in Ecology \& Evolution, 26(4), 183-192. https://doi.org/10.1016/j.tree.2011.01.009

Boyle, W. A. (2017). Altitudinal bird migration in North America. The Auk: Ornithological Advances, 134(2), 443-465. https://doi.org/10.1642/ AUK-16-228.1

Dakin, R., Segre, P. S., Straw, A. D., \& Altshuler, D. L. (2018). Morphology, muscle capacity, skill, and maneuvering ability in hummingbirds. Science, 359(6376), 653-657. https://doi.org/10.1126/science.aao7104

Dawson, W. R., Marsh, R. L., \& Yacoe, M. E. (1983). Metabolic adjustments of small passerine birds for migration and cold. American Journal of Physiology-Regulatory, Integrative and Comparative Physiology, 245(6), R755-R767. https://doi.org/10.1152/ajpregu.1983.245.6.R755

del Hoyo, J., Elliott, A., Sargatal, J., Christie, D. A., \& de Juana, E. (2005). Handbook of the Birds of the World Alive. Barcelona: Lynx Edicions.

Deveci, D., Marshall, J. M., \& Egginton, S. (2001). Relationship between capillary angiogenesis, fiber type, and fiber size in chronic systemic hypoxia. American Journal of Physiology-Heart and Circulatory Physiology, 281(1), H241-H252. https://doi.org/10.1152/ajpheart.2001.281.1.H241

Dial, K. P., Kaplan, S. R., Goslow, G. E., \& Jenkins, F. A. (1987). Structure and neural control of the pectoralis in pigeons: Implications for flight mechanics. The Anatomical Record, 218(3), 284-287. https://doi.org/ 10.1002/ar.1092180309

DuBay, S. G., Wu, Y., Scott, G. R., Qu, Y., Liu, Q., Smith, J. H., ... Bates, J. (2020). Data from: Life history predicts flight muscle phenotype and function in birds. Dryad Digital Repository, https://doi.org/10.5061/ dryad.jsxksn05s

Egginton, S. (1990). Morphometric analysis of tissue capillary supply. In R. G. Boutilier (Ed.), Vertebrate gas exchange (pp. 73-141). Berlin, Heidelberg: Springer.

Götmark, F. (1993). Conspicuous coloration in male birds is favoured by predation in some species and disfavoured in others. Proceedings of the Royal Society of London. Series B: Biological Sciences, 253(1337), 143-146. https://doi.org/10.1098/rspb.1993.0094

Grant, P. R., \& Grant, B. R. (2002). Unpredictable evolution in a 30-year study of Darwin's finches. Science, 296(5568), 707-711.

Griffiths, R., Daan, S., \& Dijkstra, C. (1996). Sex identification in birds using two CHD genes. Proceedings of the Royal Society of London, Series B: Biological Sciences, 263(1374), 1251-1256. https://doi.org/ 10.1098/rspb.1996.0184

Harrison, X. A., Blount, J. D., Inger, R., Norris, D. R., \& Bearhop, S. (2011). Carry-over effects as drivers of fitness differences in animals. Journal of Animal Ecology, 80(1), 4-18. https://doi.org/10.1111/ j.1365-2656.2010.01740.x

Hawkes, L. A., Balachandran, S., Batbayar, N., Butler, P. J., Frappell, P. B., \& Milsom, W. K., ... Bishop, C. M. (2011). The trans-Himalayan flights of bar-headed geese (Anser indicus). Proceedings of the National Academy of Sciences of the United State of America, 108(23), 9516-9519. https://doi.org/10.1073/pnas.1017295108

Hawkins, G. L., Hill, G. E., \& Mercadante, A. (2012). Delayed plumage maturation and delayed reproductive investment in birds. Biological Reviews, 87(2), 257-274. https://doi.org/10.1111/j.1469-185X.2011.00193.x

Herreid II, C. F., \& Kessel, B. (1967). Thermal conductance in birds and mammals. Comparative Biochemistry and Physiology, 21(2), 405-414. https://doi.org/10.1016/0010-406X(67)90802-X

Hsiung, A. C., Boyle, W. A., Cooper, R. J., \& Chandler, R. B. (2018). Altitudinal migration: Ecological drivers, knowledge gaps, and conservation implications. Biological Reviews, 93(4), 2049-2070. https:// doi.org/10.1111/brv.12435
Jakobsson, S., Brick, O., \& Kullberg, C. (1995). Escalated fighting behaviour incurs increased predation risk. Animal Behaviour, 49(1), 235-239. https://doi.org/10.1016/0003-3472(95)80172-3

Jones, M. R., Mills, L. S., Alves, P. C., Callahan, C. M., Alves, J. M., Lafferty, D. J., ... Good, J. M. (2018). Adaptive introgression underlies polymorphic seasonal camouflage in snowshoe hares. Science, 360(6395), 1355-1358.

Ketterson, E. D., \& Nolan, V. A. L. (1983). The evolution of differential bird migration. In Current ornithology (pp. 357-402). Boston, MA: Springer.

Kipp, F. A. (1959). Der Handflügel-Index als flugbiologisches Maß. Vogelwarte, 20(2), 77-86.

Lockwood, R., Swaddle, J. P., \& Rayner, J. M. (1998). Avian wingtip shape reconsidered: Wingtip shape indices and morphological adaptations to migration. Journal of Avian Biology, 273-292. https://doi.org/ $10.2307 / 3677110$

Lozano, G. A., Perreault, S., \& Lemon, R. E. (1996). Age, arrival date and reproductive success of male American redstarts Setophaga ruticilla. Journal of Avian Biology, 27(2), 164-170. https://doi.org/ 10.2307/3677146

Lundgren, B. O., \& Kiessling, K. H. (1988). Comparative aspects of fibre types, areas, and capillary supply in the pectoralis muscle of some passerine birds with differing migratory behaviour. Journal of Comparative Physiology B, 158(2), 165-173. https://doi.org/10.1007/ BF01075830

Lyon, B. E., \& Montgomerie, R. D. (1986). Delayed plumage maturation in passerine birds: Reliable signaling by subordinate males? Evolution, 40(3), 605-615.

Marsh, R. L., \& Dawson, W. R. (1989). Avian adjustments to cold. In Animal adaptation to cold (pp. 205-253). Berlin, Heidelberg: Springer.

McClelland, G. B., \& Scott, G. R. (2019). Evolved mechanisms of aerobic performance and hypoxia resistance in high-altitude natives. Annual Review of Physiology, 81, 561-583. https://doi.org/10.1146/annurevphysiol-021317-121527

Meyers, R. A., \& Stakebake, E. F. (2005). Anatomy and histochemistry of spread-wing posture in birds. 3. Immunohistochemistry of flight muscles and the "shoulder lock" in albatrosses. Journal of Morphology, 263(1), 12-29. https://doi.org/10.1002/jmor.10284

Morbey, Y. E., \& Ydenberg, R. C. (2001). Protandrous arrival timing to breeding areas: A review. Ecology Letters, 4(6), 663-673.

Morimoto, G., Yamaguchi, N., \& Ueda, K. (2006). Plumage color as a status signal in male-male interaction in the red-flanked bushrobin, Tarsiger cyanurus. Journal of Ethology, 24(3), 261-266. https://doi. org/10.1007/s10164-005-0187-x

Myers, J. P. (1981). A test of three hypotheses for latitudinal segregation of the sexes in wintering birds. Canadian Journal of Zoology, 59(8), 1527-1534. https://doi.org/10.1139/z81-207

Perrins, C. M. (1970). The timing of birds 'breeding seasons. Ibis, 112(2), 242-255. https://doi.org/10.1111/j.1474-919x.1970.tb00096.x

Peter, J. B., Barnard, R. J., Edgerton, V. R., Gillespie, C. A., \& Stempel, K. E. (1972). Metabolic profiles of three fiber types of skeletal muscle in guinea pigs and rabbits. Biochemistry, 11(14), 2627-2633. https://doi. org/10.1021/bi00764a013

Petit, M., \& Vézina, F. (2014). Phenotype manipulations confirm the role of pectoral muscles and haematocrit in avian maximal thermogenic capacity. Journal of Experimental Biology, 217(6), 824-830. https:// doi.org/10.1242/jeb.095703

Raveling, D. G. (1979). The annual cycle of body composition of Canada Geese with special reference to control of reproduction. The Auk, 96(2), 234-252.

Rayner, J. M. (1988). Form and function in avian flight. In R. F. Johnston (Ed.), Current ornithology (pp. 1-66). Boston, MA: Springer.

Rohwer, S. (1982). The evolution of reliable and unreliable badges of fighting ability. American Zoologist, 22(3), 531-546. https://doi. org/10.1093/icb/22.3.531 
Rosser, B. W., \& George, J. C. (1986). The avian pectoralis: Histochemical characterization and distribution of muscle fiber types. Canadian Journal of Zoology, 64(5), 1174-1185. https://doi.org/10.1139/z86-176

Rosser, B. W., Waldbillig, D. M., Wick, M., \& Bandman, E. (1994). Muscle fiber types in the pectoralis of the white pelican, a soaring bird. Acta Zoologica, 75(4), 329-336. https://doi.org/10.1111/j.1463-6395.1994. tb00970.x

Sangster, G., Alström, P., Forsmark, E., \& Olsson, U. (2010). Multilocus phylogenetic analysis of Old World chats and flycatchers reveals extensive paraphyly at family, subfamily and genus level (Aves: Muscicapidae). Molecular Phylogenetics and Evolution, 57(1), 380-392. https://doi.org/10.1016/j.ympev.2010.07.008

Scott, G. R., Egginton, S., Richards, J. G., \& Milsom, W. K. (2009). Evolution of muscle phenotype for extreme high altitude flight in the barheaded goose. Proceedings of the Royal Society B: Biological Sciences, 276(1673), 3645-3653. https://doi.org/10.1098/rspb.2009.0947

Segre, P. S., Dakin, R., Zordan, V. B., Dickinson, M. H., Straw, A. D., \& Altshuler, D. L. (2015). Burst muscle performance predicts the speed, acceleration, and turning performance of Anna's hummingbirds. elife, 4. https://doi.org/10.7554/eLife.11159

Stager, M., Swanson, D. L., \& Cheviron, Z. A. (2015). Regulatory mechanisms of metabolic flexibility in the dark-eyed junco (Junco hyemalis). Journal of Experimental Biology, 218(5), 767-777. https:// doi.org/10.1242/jeb.113472

Storz, J. F. (2018). Hemoglobin: Insights into protein structure, function, and evolution. New York, NY: Oxford University Press.

Storz, J. F., \& Scott, G. R. (2019). Life ascending: Mechanism and process in physiological adaptation to high-altitude hypoxia. Annual Review of Ecology, Evolution, and Systematics, 50(1), 503-526. https://doi. org/10.1146/annurev-ecolsys-110218-025014

Studds, C. E., \& Marra, P. P. (2005). Nonbreeding habitat occupancy and population processes: An upgrade experiment with a migratory bird. Ecology, 86(9), 2380-2385. https://doi.org/10.1890/04-1145

Swanson, D. L., Zhang, Y., \& King, M. O. (2013). Individual variation in thermogenic capacity is correlated with flight muscle size but not cellular metabolic capacity in American goldfinches (Spinus tristis).
Physiological and Biochemical Zoology, 86(4), 421-431. https://doi. org/10.1086/671447

Violle, C., Navas, M. L., Vile, D., Kazakou, E., Fortunel, C., Hummel, I., \& Garnier, E. (2007). Let the concept of trait be functional! Oikos, 116(5), 882-892. https://doi.org/10.1111/j.0030-1299.2007. 15559.x

Wedell, N., Kvarnemo, C., \& Tregenza, T. (2006). Sexual conflict and life histories. Animal Behaviour, 71(5), 999-1011.

Welch Jr, K. C., \& Altshuler, D. L. (2009). Fiber type homogeneity of the flight musculature in small birds. Comparative Biochemistry and Physiology Part B: Biochemistry and Molecular Biology, 152(4), 324-331. https://doi.org/10.1016/j.cbpb.2008.12.013

Wright, N. A., Steadman, D. W., \& Witt, C. C. (2016). Predictable evolution toward flightlessness in volant island birds. Proceedings of the National Academy of Sciences of the United State of America, 113(17), 4765-4770. https://doi.org/10.1073/pnas.1522931113

Zhu, X., Guan, Y., Signore, A. V., Natarajan, C., DuBay, S. G., Cheng, Y., ... Storz, J. F. et al. (2018). Divergent and parallel routes of biochemical adaptation in high-altitude passerine birds from the QinghaiTibet Plateau. Proceedings of the National Academy of Sciences of the United State of America, 115(8), 1865-1870. https://doi.org/10.1073/ pnas. 1720487115

\section{SUPPORTING INFORMATION}

Additional supporting information may be found online in the Supporting Information section.

How to cite this article: DuBay SG, Wu Y, Scott GR, et al. Life history predicts flight muscle phenotype and function in birds. J Anim Ecol. 2020;89:1262-1276. https://doi. org/10.1111/1365-2656.13190 